\title{
FEIJÃO-CAUPI IRRIGADO COM ÁGUA SALINA E ADUBADO COM ESTERCO BOVINO
}

Varley Andrade Fonseca' ${ }^{1}$, Cleiton Fernando Barbosa Brito², Felizarda Viana Bebé ${ }^{3}$, Alessandro de Magalhães Arantes $^{4}$, Leandro Gonçalves dos Santos ${ }^{5}$

\begin{abstract}
RESUMO
O feijão-caupi constitui-se em um dos principais componentes da dieta alimentar nas regiões Norte e Nordeste do Brasil. Objetivou-se com este trabalho avaliar o desenvolvimento do feijão-caupi submetido à irrigação com água com diferentes níveis de salinidade e adubado com esterco bovino. O experimento foi conduzido em condições de ambiente protegido em casa de vegetação. $\mathrm{O}$ delineamento experimental utilizado foi o inteiramente casualizado em esquema fatorial 2 x 5 , referente ao solo com e sem aplicação de esterco bovino (20 ton ha $\left.{ }^{-1}\right)$, e cinco níveis de salinidade da água de irrigação $\left(0,64 ; 1,32 ; 2,43 ; 3,22 ; 4,20 \mathrm{dS} \mathrm{m}^{-1}\right)$, com quatro repetições. As variáveis avaliadas foram: altura da planta, diâmetro do caule, matéria seca da parte aérea, matéria seca das raízes, matéria seca total, número e comprimento de vagens, produtividade e a condutividade elétrica do solo. A altura da planta foi reduzida linearmente à medida que se aumentou a condutividade elétrica da água de irrigação (de 0,64 para 4,20 dS m $\mathrm{d}^{-1}$ ), com uma redução de 24,07 e 32,34\%, com e sem aplicação de esterco, respectivamente. A produtividade apresentou redução de $71,42 \%$ no tratamento que recebeu esterco e de $80,99 \%$ sem aplicação de esterco. Todas as variáveis analisadas foram influenciadas pela salinidade da água de irrigação promovendo redução do menor para o maior nível de salinidade. A aplicação de esterco bovino contribuiu para diminuir os efeitos da salinidade da água de irrigação.
\end{abstract}

Palavras-chave: salinidade, matéria orgânica, Vigna unguiculata

\section{ABSTRACT \\ COWPEA IRRIGATED WITH SALINE WATER AND FERTILIZED WITH CATTLE MANURE}

Cowpea constitutes one of the main components of the diet in the North and Northeast of Brazil. The objective of this study was to evaluate the development of cowpea subjected to irrigation with water with different salinity levels and fertilized with cattle manure. The experiment was conducted under greenhouse conditions in a greenhouse. The experimental design was completely randomized in a factorial $2 \times 5$, covering the soil with and without application of manure $\left(20\right.$ ton $\left.\mathrm{a}^{-1}\right)$ and five levels of irrigation water salinity $\left(0.64 ; 1.32 ; 2.43 ; 3.22 ; 4.20 \mathrm{dS} \mathrm{m}^{-1}\right)$, with four replications. The variables evaluated were: plant height, stem diameter, dry matter of shoot, root dry matter, total dry matter, number and length of pods, productivity and soil electrical conductivity. Plant height was reduced linearly as it increased the electrical conductivity of the irrigation water $\left(0.64\right.$ to $\left.4.20 \mathrm{dS} \mathrm{m}^{-1}\right)$, with a decrease of $24.07 \%$ and 32.34, with or without application of manure, respectively. Productivity Decreased by $71.42 \%$ in the treatment que received manure and $80.99 \%$ without application of manure. All variables were influenced by salinity smaller reduction promoting irrigation water to the highest level of salinity. The application of manure helps to reduce the effects of irrigation water salinity.

Keywords: salinity, organic matter, Vigna unguiculata

\section{Recebido para publicação em 06/07/2016. Aprovado em 10/10/2016.}

1 - Engenheiro Agrônomo, Mestrando em Produção Vegetal no Semiárido, IF BAIANO/Guanambi-BA. varley.ibce@ig.com.br

2 - Engenheiro Agrônomo, Mestrando em Produção Vegetal no Semiárido, IF BAIANO/Guanambi-BA. cleiton.ibce@hotmail.com

3 - Engenheiro Agrônomo, Professor do IF BAIANO/Guanambi-BA. felizvc@hotmail.com

4 - Engenheiro Agrônomo, Professor do IF BAIANO/Guanambi-BA. leandro.ifpb@gmail.com

5- Engenheiro Agrônomo, Professor do IF BAIANO/Guanambi-BA. arantes2005@yahoo.com.br 


\section{INTRODUÇÃO}

O feijão-caupi (Vigna unguiculata (L.) Walp.) constitui-se em um dos principais componentes da dieta alimentar nas regiões Norte e Nordeste do Brasil, especialmente na zona rural (NASCIMENTO et al., 2012). Nessas regiões, para maioria dos pequenos e médios agricultores que a cultivam, esta cultura é tipicamente de subsistência com produção destinada para consumo doméstico e venda da produção excedente.

O cultivo do caupi se concentra na estação das chuvas devido à falta de água para irrigação no período da seca. A produtividade desta cultura no Nordeste é bastante incipiente alcançando valor de $404 \mathrm{~kg} \mathrm{ha}^{-1}$ (CONAB 2016). Esses resultados em muitos locais estão atrelados ao déficit hídrico e a deficiência nutricional dos solos cultivados (BELTRÃO JÚNIOR et al., 2012). Uma forma de amenizar os efeitos da escassez hídrica e nutrição inadequada das plantas, que tem como consequência o baixo rendimento da cultura, é a utilização da irrigação e de adubos orgânicos para recuperar a fertilidade dos solos.

A irrigação é uma das tecnologias aplicadas na agricultura que mais tem contribuído para o aumento na produção de alimentos, no entanto esta prática deve ser usada de forma racional, uma vez que as condições do Nordeste (alta evapotranspiração, baixa pluviosidade e os elevados teores de sais na água de irrigação) podem causar salinização nos solos (BRASILEIRO, 2009). Além disso, em muitas áreas irrigadas do mundo, o suprimento de água de boa qualidade disponível para irrigação pode não ser suficiente para a manutenção da agricultura irrigada, assim tem-se como alternativa o uso de água do lençol freático ou mesmo de drenagem, as quais geralmente apresentam baixa qualidade. Por isto, é necessário avaliar sua qualidade e realizar um manejo rigoroso visando sua utilização de forma sustentável (TRAVASSOS et al., 2012).

Os efeitos da salinidade sobre as plantas são: seca fisiológica, proveniente da diminuição do potencial osmótico, desbalanceamento nutricional devido à elevada concentração iônica, especialmente o sódio, que inibe a absorção de outros nutrientes e efeito tóxico de íons, particularmente o cloro e o sódio (SILVA et al., 2011a).

Os sais reduzem consideravelmente $\mathrm{o}$ rendimento das culturas, pois interferem de maneira direta e indireta no desenvolvimento das plantas. A redução do potencial osmótico causado pelo excesso de sais solúveis na solução do solo promove um aumento das forças de retenção de água, a qual poderá atingir um nível em que as plantas não terão força suficiente para superar o potencial no solo e, em consequência, a planta não absorve água e nutrientes, devido à condição de estresse hídrico (DIAS \& BLANCO, 2010).

Tendo em vista a baixa disponibilidade de água com boa qualidade para irrigação na região semiárida, é fundamental o desenvolvimento de novas técnicas que permitam a utilização de águas com qualidade inferior na produção agrícola. Um manejo estratégico para utilização de água de elevada salinidade é a sua mistura com água de baixa concentração de sais, promovendo a inserção dessas águas no sistema de produção vegetal em regiões que sofrem com veranicos prolongados. Esta alternativa permite a exploração de forma racional dos recursos hídricos e das culturas desenvolvidas no semiárido e fixa o homem no campo (SILVA et al., 2014).

Outra opção para inserção de águas de baixa qualidade no sistema produtivo é a escolha de espécies tolerantes aos efeitos da salinidade. Dentre as culturas utilizadas no Nordeste, o feijão-caupi é considerada uma espécie moderadamente tolerante à salinidade da água de irrigação, mesmo em solos com até $3,3 \mathrm{dS} \mathrm{m}^{-1}$ não apresenta nenhuma redução na produtividade (AYERS \& WESTCOT, 1999).

Além das estratégias relatadas, a adubação orgânica pode ser um excelente condicionador de solo, e pode promover melhores condições ao desenvolvimento das culturas, por influenciar as características químicas, físicas e biológicas do solo. O esterco bovino é fonte de matéria orgânica, e geralmente está disponível nas pequenas propriedades onde a criação de animais complementa a renda familiar. Funciona como fonte de nutrientes, apresenta cargas de superfície que contribuem para o aumento da capacidade de troca de cátions (CTC) do solo e, devido a sua alta reatividade, regula a disponibilidade de vários nutrientes, em especial os micronutrientes, bem como a atividade de elementos potencialmente fitotóxicos como $\mathrm{Al}^{3+}$ e $\mathrm{Mn}^{2+}$, em solos ácidos, e com presença de metais pesados (ZANDONADI et al., 2014).

A matéria orgânica afeta as propriedades físicas através da agregação de partículas e promove maior retenção de água e aeração do solo. Biologicamente, fornece energia para os microorganismos, que são 
responsáveis pela ciclagem e disponibilização de nutrientes às plantas.

Neste contexto, o objetivo do presente trabalho foi avaliar o desenvolvimento do feijão-caupi submetido à irrigação utilizando água com de diferentes níveis de salinidade e adubado com esterco bovino.

\section{MATERIAL E MÉTODOS}

O experimento foi conduzido em condições de ambiente protegido na casa de vegetação do setor de agricultura do Instituto Federal de Educação Ciência e Tecnologia Baiano - Campus Guanambi, localizado no Município de Guanambi,
Micro Região da Serra Geral, Sudoeste da Bahia, com latitude de 14'17'27' sul, longitude de 42 46'53" oeste de Greenwich, altitude de $537 \mathrm{~m}$, precipitação de $680 \mathrm{~mm}$ e temperatura média de $26^{\circ} \mathrm{C}$ (DONATO et al., 2010).

$\mathrm{O}$ experimento foi realizado entre julho e outubro de 2014. Os dados climáticos foram obtidos por uma estação meteorológica próxima a casa de vegetação onde foi conduzido o experimento. Nas Figuras 1A e 1B estão apresentadas a temperatura máxima, média e mínima, umidade relativa e velocidade do vento referente ao período de condução do experimento até a sua colheita (22 de julho a 15 de outubro).
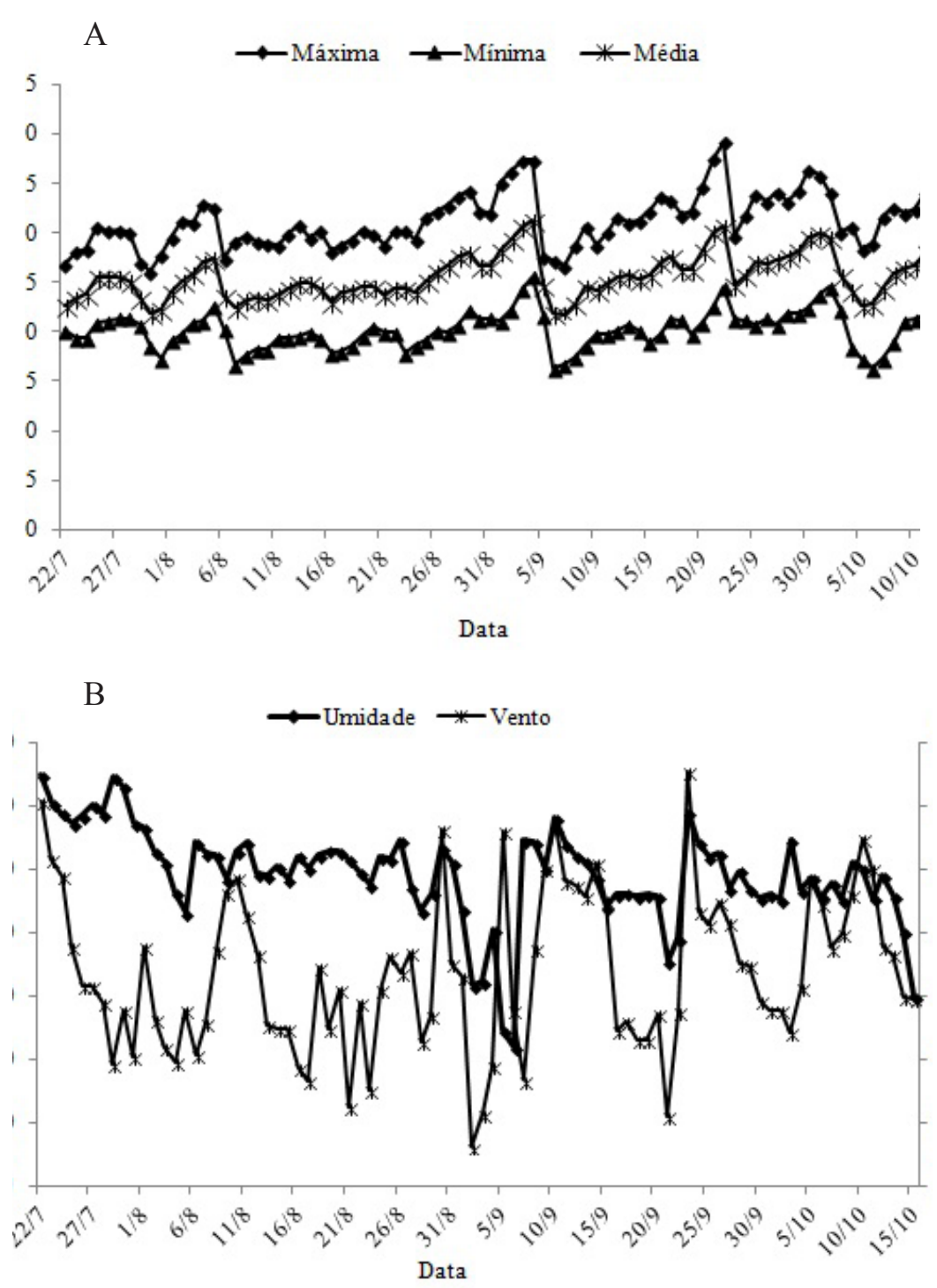

Figura 1. Temperatura máxima, média e mínima (A) e umidade relativa e velocidade do vento (B) durante o período de 22 de junho a 15 de outubro de 2014. Estação automática. IF Baiano - Campus Guanambi, 2014. 
O solo utilizado no experimento foi um Latossolo Vermelho-Amarelo de textura média, retirado de uma camada de $0-20 \mathrm{~cm}$ de profundidade e passado em peneira de malha de $4 \mathrm{~mm}$, para determinação das características químicas (Quadro 1).

$\mathrm{O}$ delineamento experimental utilizado foi $\mathrm{o}$ inteiramente casualizado em esquema fatorial $2 \mathrm{x}$ 5 , referente ao solo com e sem aplicação de esterco bovino, e cinco níveis de salinidade da água de irrigação $\left(0,64 ; 1,32 ; 2,43 ; 3,22 ; 4,20 \mathrm{dS} \mathrm{m} \mathrm{m}^{-1}\right)$, com quatro repetições, compondo 40 unidades experimentais. Cada unidade experimental foi representada por uma planta cultivada em vaso de polietileno com capacidade de $20 \mathrm{~kg}$. A dose de esterco aplicada foi referente a 20 ton $\mathrm{ha}^{-1}$, bem próxima da dose de 17,3 ton ha ${ }^{-1}$ que promoveu maior rendimento de feijão-caupi em experimento realizado por Pereira et al. (2013), em clima semiárido. $\mathrm{O}$ esterco utilizado foi proveniente do setor de bovinocultura do IF Baiano, campus Guanambi.

Os diferentes níveis de salinidade da água de irrigação foram obtidos pela mistura de água de menor salinidade $\left(0,64 \mathrm{dS} \mathrm{m}^{-1}\right)$, proveniente do canal de abastecimento do setor de agricultura com outra de maior nível de salinidade $(4,20 \mathrm{dS}$ $\mathrm{m}^{-1}$ ), proveniente de um lote situado no perímetro irrigado de Ceraíma, distrito de Guanambi-BA (Quadro 2).

A semeadura foi realizada dia 22 de julho de 2014, a uma profundidade de $2 \mathrm{~cm}$, com três sementes por vaso, sendo utilizada a cultivar 'Sempre Verde'. O desbaste foi realizado aos sete dias após o plantio, deixando-se somente a planta mais vigorosa.

A irrigação foi realizada diariamente aplicandose a mesma quantidade de água para todas as unidades experimentais, mantendo-se a umidade próxima à capacidade de "vaso". Para isso diariamente pesava-se um vaso separado com planta para determinar a água evapotranspirada e a quantidade a ser disponibilizada a cada dia. A irrigação dos vasos com as águas de diferentes salinidades foi realizada somente após o desbaste, sendo que antes todas as unidades experimentais foram irrigadas com a água de menor salinidade $\left(0,64 \mathrm{dS} \mathrm{m}^{-1}\right)$ proveniente do canal de abastecimento do setor de agricultura.

No final do experimento, aos 85 dias após a semeadura, foram avaliadas as seguintes variáveis: altura da planta, diâmetro do caule, matéria seca da parte aérea, matéria seca das raízes e matéria seca total.

Para determinação da altura da planta foi utilizada uma régua, o diâmetro do caule foi determinado com a utilização de paquímetro, a leitura foi realizada no colo da planta próximo ao solo.

A matéria seca da parte área foi determinada através do corte da planta rente ao solo e posterior envio ao laboratório de solos, onde foram acondicionadas em sacos de papel furados e submetidas à secagem em estufa de circulação forçada de ar, à temperatura de $65^{\circ} \mathrm{C}$, até atingir peso constante, em seguida pesadas em balança de precisão.

Quadro 1. Caracterização química do solo utilizado no cultivo de feijão-caupi. IF Baiano - Campus Guanambi, 2014

\begin{tabular}{|c|c|c|c|c|c|c|c|c|c|c|c|c|}
\hline Profundidade & $\mathrm{pH}$ & $\mathrm{P}$ & $\mathrm{K}^{+}$ & $\mathrm{Ca}^{2+}$ & $\mathrm{Mg}^{2+}$ & $\mathrm{Al}^{3+}$ & $\mathrm{H}^{+}$ & S.B & $\mathrm{t}$ & $\mathrm{T}$ & V & $\mathrm{m}$ \\
\hline & $\mathrm{H}_{2} \mathrm{O}$ & $\mathrm{mg} \mathrm{dm}^{-3}$ & ---- & - & ----- & $\operatorname{nol}_{\mathrm{c}} \mathrm{d}$ & 3 & - & --- & ---- & \multicolumn{2}{|c|}{----- \% } \\
\hline $0-20 \mathrm{~cm}$ & 7,0 & 23 & 0,51 & 2,9 & 1,4 & 0,1 & 1,2 & 4,8 & 4,9 & 6,1 & 79 & 2 \\
\hline
\end{tabular}

Quadro 2. Porcentagem de água do canal e do lote de Ceraíma para produção de 100 litros de água das diferentes salinidades. IF Baiano - Campus Guanambi, 2014

\begin{tabular}{ccc}
\hline Salinidade da Água $\left(\mathrm{dS} \mathrm{m}^{-1}\right)$ & Água do canal $(\%)$ & Água do lote $(\%)$ \\
\hline 0,64 & 100,00 & 0 \\
1,32 & 83,35 & 16,65 \\
2,43 & 50,00 & 50,00 \\
3,22 & 28,60 & 71,40 \\
4,20 & 0 & 100,00 \\
\hline
\end{tabular}


A matéria seca de raízes foi determinada através da retirada cuidadosa de todo o solo do sistema radicular, o qual posteriormente foi lavado com água. Após isso as raízes foram levadas ao laboratório, acondicionadas em sacos de papel furados e levados para secagem em estufa de circulação forçada de ar, à temperatura de 65 ${ }^{\circ} \mathrm{C}$, até atingir peso constante, e posteriormente realizou-se a pesagem seca em balança de precisão.

As variáveis produtivas avaliadas foram número de vagens por planta através da contagem direta, comprimento médio de vagens com utilização de fita métrica e a produtividade através da pesagem em balança de precisão dos grãos produzidos por planta $\left(\mathrm{g} \mathrm{planta}^{-1}\right)$.

A variável do solo avaliada foi à condutividade elétrica. Para sua determinação, após retirada as plantas e o sistema radicular dos vasos, foi coletada uma amostra de solo de cada vaso. As amostras coletadas foram acondicionadas em sacos plásticos e levadas para o laboratório de solos, onde foram secadas ao ar e posteriormente destorroada e passadas em peneira de $2 \mathrm{~mm}$, sendo após isso novamente acondicionados em sacos plásticos.

A condutividade elétrica foi determinada a partir da pasta saturada, a qual foi preparada utilizandose $400 \mathrm{~g}$ de solo e adicionando água deionizada até a formação de uma pasta brilhante. $\mathrm{O}$ extrato saturado foi obtido mediante sucção à vácuo. Através do extrato da pasta saturada, seguindo a metodologia descrita por Richards (1954), foi determinada a condutividade elétrica.

Procedeu-se a análise de variância e os desdobramentos sempre que a interação foi significativa. Para o fator quantitativo, relativo aos níveis de salinidade da água de irrigação, foram ajustadas equações de regressão com base na adequação do modelo ao fenômeno estudado, significância dos parâmetros da regressão pelo teste $\mathrm{t}$ a $5 \%$ de probabilidade e no coeficiente de determinação ajustado $\left(\mathrm{R}^{2}\right)$ e o fator qualitativo relativo à aplicação de esterco bovino foi analisado por meio de comparação de médias com base no teste de Tukey a $5 \%$ de probabilidade. Para realizar a análise estatística, utilizou-se o programa estatístico "R", R Development Core Team (2012).

\section{RESULTADOS E DISCUSSÃO}

A planta de feijão-caupi apresentou diferença $(p<0,05)$ na altura enquanto a matéria seca da parte aérea e matéria seca total apresentaram diferença $(\mathrm{p}<0,01)$ para a interação aplicação de esterco e salinidade da água de irrigação indicando assim dependência destes fatores. $\mathrm{O}$ diâmetro do caule não foi influenciado pela interação, porém houve efeito da aplicação de esterco e da salinidade da água $(\mathrm{p}<0,01)$ de forma isolada. Já a matéria seca de raízes foi influenciada $(\mathrm{p}<0,01)$ de forma isolada pela salinidade da água. A salinidade da água influenciou $(\mathrm{p}<0,01)$ todas as variáveis de crescimento avaliadas. Não houve efeito da aplicação de esterco somente para a variável matéria seca de raízes (Quadro 3).

A altura das plantas diferiram entre os tratamentos $(p<0,05)$ com e sem esterco apenas nos níveis de

Quadro 3. Resumo da análise de variância com os respectivos quadrados médios para as variáveis de crescimento de feijão-caupi em função da irrigação utilizando água com diferentes níveis de salinidade e com e sem aplicação de esterco bovino. IF Baiano - Campus Guanambi, 2014

\begin{tabular}{ccclccc}
\hline \multirow{2}{*}{ Fonte de Variação } & \multirow{2}{*}{ GL } & \multicolumn{5}{c}{ Quadrados Médios } \\
\cline { 3 - 7 } & & ALT $(\mathrm{cm})$ & DC $(\mathrm{cm})$ & MSPA $(\mathrm{g})$ & MSR $(\mathrm{g})$ & MST $(\mathrm{g})$ \\
\hline Esterco (E) & 1 & $10,51^{*}$ & $0,400^{* *}$ & $322,91^{* *}$ & $0,34^{\mathrm{NS}}$ & $344,22^{* *}$ \\
Salinidade (S) & 4 & $53,96^{* *}$ & $0,052^{* *}$ & $274,92^{* *}$ & $7,26^{* *}$ & $370,08^{* *}$ \\
E x S & 4 & $6,33^{*}$ & $0,016^{\text {NS }}$ & $20,27^{* *}$ & $0,15^{\mathrm{NS}}$ & $23,76^{* *}$ \\
Resíduo & 30 & 2,01 & 0,007 & 4,01 & 0,10 & 4,28 \\
\hline Média & & 19,24 & 0,86 & 10,61 & 1,75 & 12,36 \\
CV (\%) & 7,37 & 9,61 & 18,88 & 18,04 & 16,75 \\
\hline
\end{tabular}

ALT - altura, DC - diâmetro do caule, MSPA - matéria seca da parte aérea, MSR - matéria seca de raízes e MST - matéria seca total.

${ }^{N S}$ não significativo, * significativo a $5 \% \mathrm{e}^{* *}$ significativo a $1 \%$ de probabilidade pelo teste $\mathrm{F}$. 
salinidade da água de 2,43 e $4,20 \mathrm{dS} \mathrm{m}^{-1}$. As médias para o tratamento com esterco foram 19,63 e 17,50 $\mathrm{cm}$, respectivamente, e, para o tratamento sem esterco, 16,38 e $15,13 \mathrm{~cm}$, respectivamente. Silva et al. (2011b) verificaram que os níveis crescentes de sais da água de irrigação prejudicaram o crescimento de plantas de feijão-caupi, no entanto, com menos intensidade em solo que recebeu aplicação de biofertilizante bovino, corroborando com os resultados da presente pesquisa.

O diâmetro do caule apresentou maior média, $0,96 \mathrm{~cm}$, com aplicação de esterco, diferindo estatisticamente do valor médio de $0,76 \mathrm{~cm}$ sem a aplicação do mesmo. Isto possivelmente se deve pela maior disponibilização de nutrientes para a planta de feijão, fornecidos pelo esterco.

$\mathrm{Na}$ Figura 2A, observa-se que a altura da planta foi reduzida linearmente à medida que se aumentou a condutividade elétrica da água de irrigação, com uma redução de 24,07 e 32,34\%, com e sem aplicação de esterco, respectivamente. Lima et al. (2007) em condições de semiárido e em casa de vegetação, verificaram uma redução na altura de feijão-caupi em cerca de 42,86\% nas plantas irrigadas com o maior nível salino $\left(5,0 \mathrm{dS} \mathrm{m}^{-1}\right)$, redução maior que a encontrada no presente estudo.

O diâmetro do caule decresceu linearmente com o aumento da salinidade da água de irrigação (Figura 2B). A redução foi de $20,00 \%$, de 0,95 para $0,76 \mathrm{~cm}$. Silva et al. (2009), estudando o desenvolvimento vegetativo do feijão-caupi irrigado com água salina em casa de vegetação, observaram também uma redução de $34,69 \%$ no diâmetro do caule com o aumento da salinidade da água de irrigação de $0,5 \mathrm{dS} \mathrm{m}^{-1}$ para $5,0 \mathrm{dS} \mathrm{m}^{-1}$. Os mesmos autores verificaram que esta variável foi a menos afetada pelas concentrações de sais.

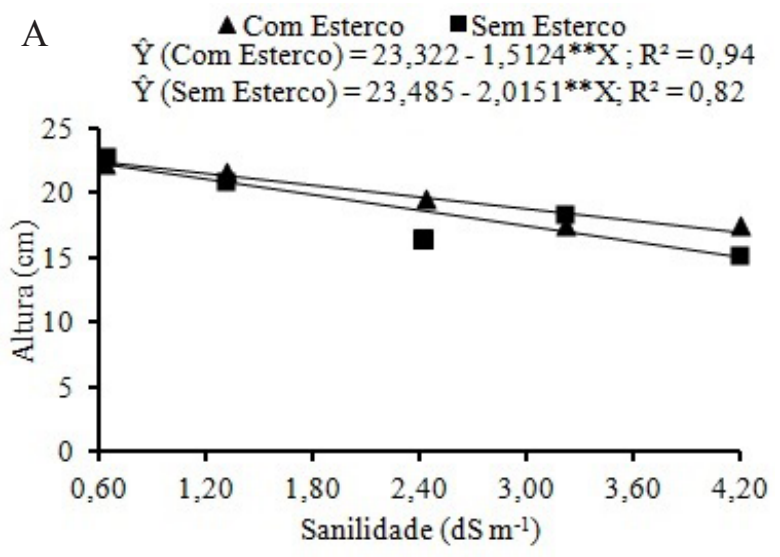

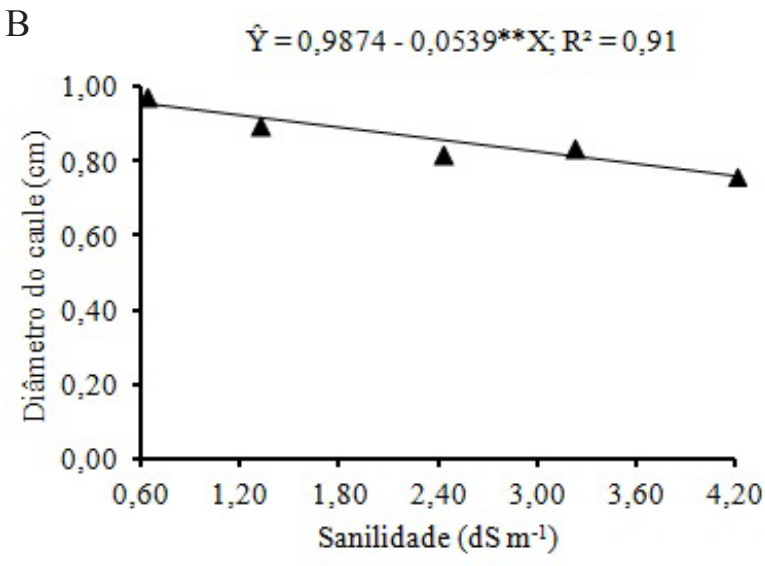

Figura 2. Altura (A) de feijão-caupi irrigado com água de diferentes níveis de salinidade e com e sem aplicação de esterco e diâmetro do caule (B) em função da irrigação utilizando água com diferentes níveis de salinidade. IF Baiano - Campus Guanambi, 2014.

Segundo Coelho et al. (2013), a redução do crescimento do feijoeiro Vigna sob estresse salino pode ser explicada pela diminuição do potencial osmótico da solução do solo, a qual ocasiona maior dificuldade de absorção de água, como também pela possibilidade da ocorrência de toxicidade iônica em função do acúmulo excessivo de determinados íons.

O ajuste osmótico pode ser considerado um mecanismo adaptativo que proporciona a manutenção, sob baixos potenciais hídricos, da turgescência e de seus processos dependentes, como o fluxo de água para as células em crescimento e alongamento celular (Silveira et al., 2009). Os efeitos da salinidade estão em acordo com Larcher (2006), e constitui um fator progressivo de distúrbios fisiológicos nas plantas e compromete o fechamento e abertura dos estômatos, além da inibir o crescimento e produção de diversas culturas.

A matéria seca da parte aérea (MSPA) de feijãocaupi diferiu significativamente quando cultivado com e sem esterco somente nos tratamentos que utilizaram água contendo os menores níveis de salinidade $\left(0,64 ; 1,32\right.$ e $\left.2,43 \mathrm{dS} \mathrm{m}^{-1}\right)$. Os maiores valores da MSPA foram obtidos com a aplicação do esterco. Este resultado pode ser explicado pela atenuação dos efeitos dos sais no solo e planta quando em níveis menores, promovido pela matéria orgânica adicionada.

\section{REVENG 427-438p.}


A matéria seca da parte aérea do feijoeiro reduziu linearmente com o aumento dos níveis de salinidade na água de irrigação. A redução foi de $81,33 \%$, de 22,17 para 4,14 g no tratamento que recebeu esterco e de $82,51 \%$ no que não recebeu, sendo de 12,92 a 2,27 gramas (Figura 3A).

Esta redução provavelmente ocorreu devido ao efeito osmótico dos sais em torno das raízes levando a planta a exercer um controle maior na abertura dos estômatos para evitar a excessiva perda de água por transpiração. Coelho et al. (2013) explica que a redução da evapotranspiração da cultura está relacionada com a ação do componente osmótico que, por sua vez, dificulta a absorção de água pela planta. Como consequência, o feijoeiro apresenta o seu crescimento afetado pelos níveis de salinidade do solo com alterações morfológicas (folhas menores e menor número de folhas) que também contribuíram para um consumo menor de água. Além disso, Souza et al. (2011) relatam que o fechamento dos estômatos diminui a difusão do $\mathrm{CO}_{2}$ para dentro das células com consequente redução na taxa de fotossíntese e no crescimento da planta.

A matéria seca de raízes reduziu linearmente com o aumento do nível de salinidade da água independente da aplicação de esterco (Figura 3B). A variação foi de $79,15 \%$ do menor para o maior valor, ou seja, de 2,83 a 0,59 gramas.

Resultado semelhante foi encontrado por Lima et al. (2007), em condições de semiárido e em casa de vegetação, que verificaram uma redução de $76,14 \%$ da matéria seca de raízes do menor $(0,5 \mathrm{dS}$ $\left.\mathrm{m}^{-1}\right)$ para o maior $\left(5,0 \mathrm{dS} \mathrm{m}^{-1}\right)$ nível de salinidade da água. Munns \& Tester (2008) relatam que a inibição no crescimento do sistema radicular sob condições salinas pode ser atribuída à redução da fotossíntese.

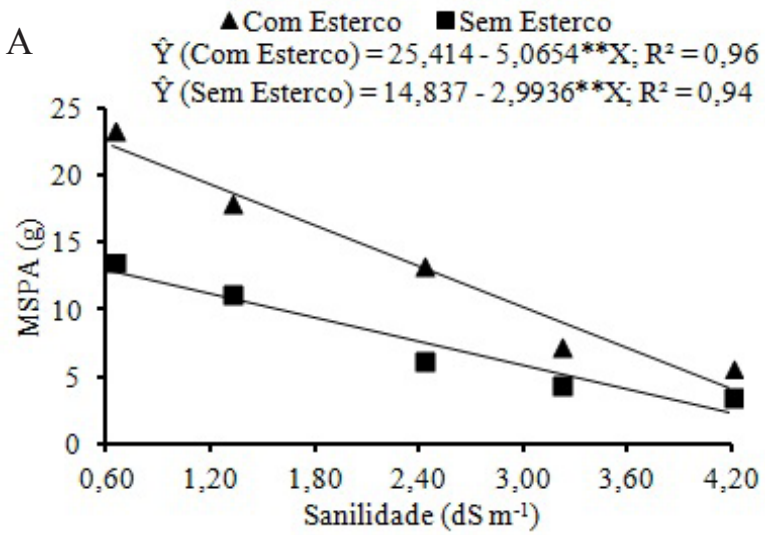

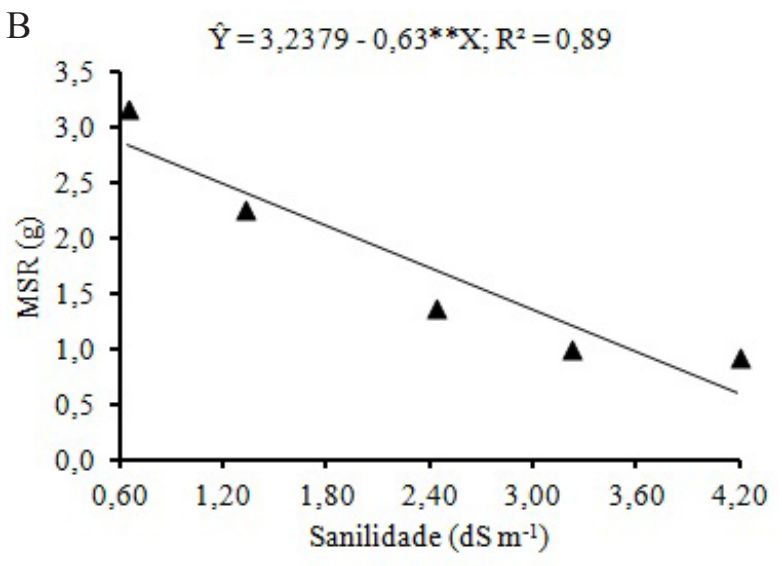

Figura 3. Matéria seca da parte aérea (A) de feijão-caupi irrigado com água de diferentes níveis de salinidade e com e sem aplicação de esterco, e matéria seca de raiz (B) em função da irrigação utilizando água com diferentes níveis de salinidade. IF Baiano - Campus Guanambi, 2014.

A matéria seca total apresentou as maiores médias $(26,71 ; 20,25$ e $14,86 \mathrm{~g})$ com a aplicação de esterco para os níveis de salinidade $(0,64$; 1,32 e $2,43 \mathrm{dS} \mathrm{m}^{-1}$ ), respectivamente, diferindo estatisticamente do tratamento sem a aplicação de esterco. Para os demais níveis de salinidade não houve diferença estatística.

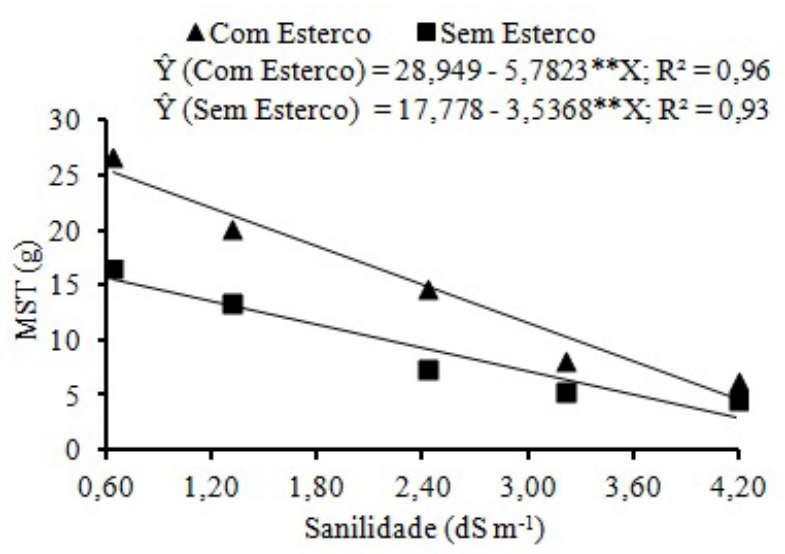

Figura 4. Matéria seca total de feijão-caupi irrigado com água de diferentes níveis de salinidade e com e sem aplicação de esterco. IF Baiano - Campus Guanambi, 2014.

Observa-se no quadro 4 que a variável condutividade elétrica do solo foi influencia em nível de $5 \%$ de significância pela interação 
aplicação de esterco e salinidade da água, não sendo afetada pela aplicação de esterco de forma isolada. $\mathrm{O}$ número de vagens foi influenciado $(\mathrm{p}<0,01)$ pela aplicação de esterco e salinidade da água de forma isolada. O comprimento de vagens e produtividade apresentaram efeito significativo $(\mathrm{p}<0,05$ e $\mathrm{p}<0,01$ respectivamente), para a interação aplicação de esterco e salinidade da água, indicando dependência desses fatores.

O solo apresentou maior valor de condutividade elétrica $\left(25,97 \mathrm{dS} \mathrm{m}^{-1}\right)$ sem aplicação de esterco diferindo estatísticamente do valor 14,20 dS m${ }^{-1}$ com a aplicação de esterco somente no maior nível salinidade da água $\left(4,20 \mathrm{dS} \mathrm{m}^{-1}\right)$.

O feijão-caupi apresentou maior número de vagens $(3,55)$ com a aplicação de esterco diferindo estatisticamente da média de 2,30 sem a aplicação de esterco. Pereira et al. (2013), estudando a produção de feijão vigna sob adubação orgânica em ambiente semiárido, observaram aumento no número de vagens com aplicação de esterco bovino ao solo.

A condutividade elétrica do solo aumentou linearmente com a aplicação da água com diferentes níveis de salinidade (Figura 5A). Apresentou acréscimo de $164,41 \%$ do menor valor, $5,62 \mathrm{dS} \mathrm{m}^{-1}$ para o maior valor, $14,86 \mathrm{dS} \mathrm{m}^{-1}$ no tratamento que recebeu esterco e de $1271,95 \%$ sem aplicação, ou seja, de 1,64 dS m ${ }^{-1}$ para 22,50 $\mathrm{dS} \mathrm{m}^{-1}$. Esses valores elevados são explicados pelo fato da inexistência de aplicação de fração de lixiviação para reduzir a acumulação de sais no solo. Resultado semelhante foi encontrado por Silva et al. (2011b), que avaliando a interação entre salinidade e biofertilizante bovino na cultura do feijão-de-corda verificaram acréscimo da condutividade elétrica do solo do menor $(0,8 \mathrm{dS}$ $\left.\mathrm{m}^{-1}\right)$ para o maior $\left(6,0 \mathrm{dS} \mathrm{m}^{-1}\right)$ nível de salinidade.

$\mathrm{Na}$ Figura 5B, está apresentada a variável número de vagens, que reduziu linearmente com o aumento dos níveis de salinidade da água de irrigação independente da aplicação de esterco, apresentando uma redução de $68,72 \%$ do menor $\left(0,64 \mathrm{dS} \mathrm{m}^{-1}\right)$ para o maior $\left(4,20 \mathrm{dS} \mathrm{m}^{-1}\right)$ nível de salinidade, cujo os valores foram de 4,38 e 1,37 vagens, respectivamente.
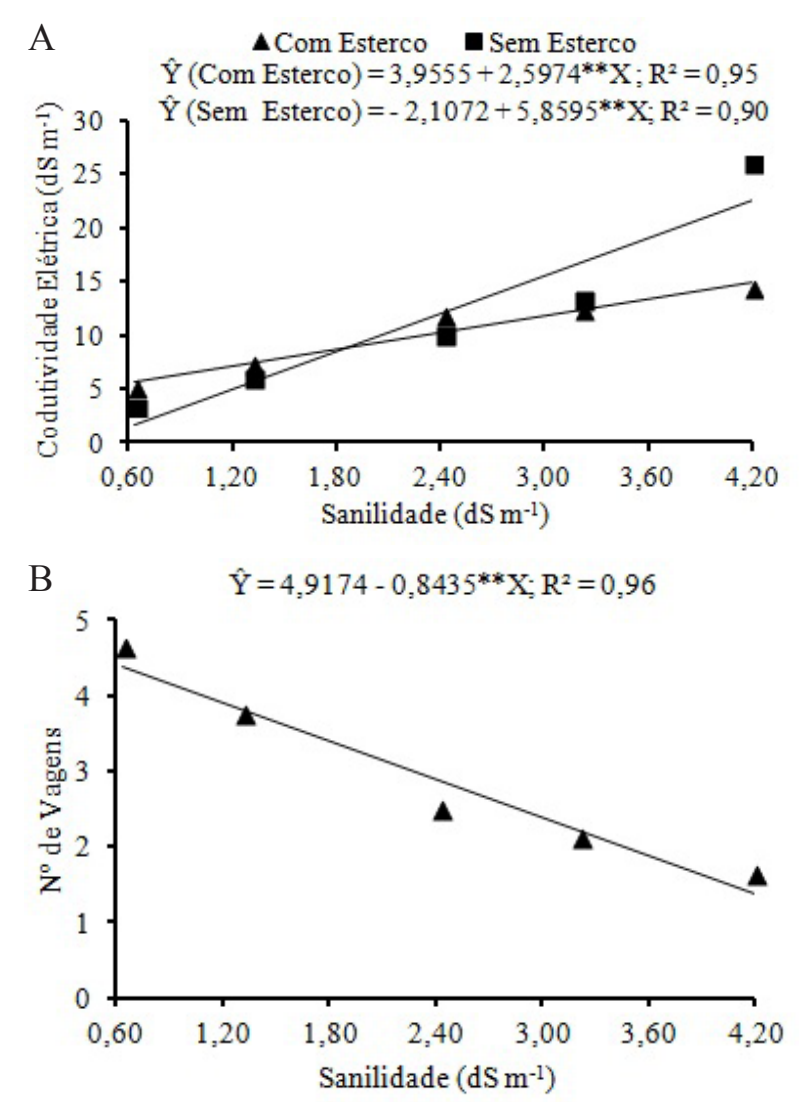

Figura 5. Condutividade elétrica (A) do extrato de saturação do solo cultivado com feijãocaupi irrigado utilizando água com diferentes níveis de salinidade e com e sem aplicação de esterco e número de vagens (B) em função da irrigação utilizando água com água de diferentes níveis de salinidade. IF Baiano Campus Guanambi, 2014.

O comprimento de vagens apresentou os maiores valores 18,33 e 16,92 cm com a aplicação de esterco, os quais diferiram estatisticamente dos valores 14,00 e $14,00 \mathrm{~cm}$ obtidos sem a aplicação de esterco nos níveis de salinidade de 2,43 e 4,20 $\mathrm{dS} \mathrm{m}^{-1}$, respectivamente. Para os demais níveis de salinidade não houve diferença estatística entre os valores.

A produtividade do feijão-caupi apresentou maiores valores com a aplicação de esterco $(15,82$; 10,$98 ; 9,09 ; 6,07$ e 5,06 g planta $^{-1}$ para os tratamentos 0,$64 ; 1,32 ; 2,43 ; 3,22 ; 4,20 \mathrm{dS} \mathrm{m}^{-1}$ respectivamente) diferindo estatisticamente dos valores obtidos sem aplicação de esterco $(7,95 ; 5,31 ; 3,36 ; 2,61$ e $2,04 \mathrm{~g}$ planta $^{-1}$ para os tratamentos 0,$64 ; 1,32 ; 2,43 ; 3,22$; $4,20 \mathrm{dS} \mathrm{m}^{-1}$ respectivamente).

\section{REVENG}


Quadro 4. Resumo da análise de variância com os respectivos quadrados médios para a variável condutividade elétrica do solo e as variáveis de produção de feijão-caupi em função da irrigação utilizando água com diferentes níveis salinidade e com ou sem aplicação de esterco bovino. IF Baiano - Campus Guanambi, 2014

\begin{tabular}{cccccc}
\hline & & \multicolumn{4}{c}{ Quadrados Médios } \\
\cline { 3 - 6 } Fonte de variação & GL & $\begin{array}{c}\text { Condutividade } \\
\left.\text { elétrica }(\mathrm{dS} \mathrm{m})^{-1}\right)\end{array}$ & Número de vagens & $\begin{array}{c}\text { Comprimento de } \\
\text { vagens }(\mathrm{cm})\end{array}$ & $\begin{array}{c}\text { Produtividade } \\
\left(\mathrm{g} \mathrm{planta}^{-1}\right)\end{array}$ \\
\hline Esterco (E) & 1 & $26,98^{\mathrm{NS}}$ & $15,63^{* *}$ & $45,88^{* *}$ & $265,28^{* *}$ \\
Salinidade (S) & 4 & $303,06^{* *}$ & $12,16^{* *}$ & $6,49^{*}$ & $89,10^{* *}$ \\
E x S & 4 & $66,61^{*}$ & $0,31^{\mathrm{NS}}$ & $5,04^{*}$ & $7,70^{* *}$ \\
Resíduo & 30 & 22,70 & 0,58 & 1,86 & 1,47 \\
\hline Média & & 10,91 & 2,93 & 16,56 & 6,83 \\
CV (\%) & 43,66 & 25,92 & 8,23 & 17,77 \\
\hline
\end{tabular}

NS não significativo, * significativo a $5 \%$ e ** significativo a $1 \%$ de probabilidade pelo teste $\mathrm{F}$.

Observa-se pelos valores médios que, mesmo no tratamento testemunha com o menor nível de salinidade, a produtividade foi relativamente baixa, isso se deve ao abortamento de flores promovido por ocorrência de temperaturas elevadas no período de floração (Figura 1A). Segundo Ellis et al. (1994), altas temperaturas interferem na produção de feijão-caupi exercendo influência sobre $o$ abortamento de flores, o vingamento e a retenção final de vagens, afetando também o número de sementes por vagem.

As maiores médias de produtividade obtidas com a aplicação de esterco indicam as contribuições da adubação orgânica no que se refere à amenização dos efeitos salinos e a maior nutrição da planta.

O comprimento de vagens foi a variável que apresentou menor redução com o aumento do nível de salinidade da água. Com a aplicação de esterco, não houve efeito significativo dos diferentes níveis de salinidade. Sem a aplicação de esterco, verificouse uma redução de $12,39 \%$ do maior valor, 16,47 $\mathrm{cm}$ para o menor valor $14,43 \mathrm{~cm}$ (Figura 6A).

A produtividade apresentou redução de $71,42 \%$ do maior valor, $14,37 \mathrm{~g}$ planta $^{-1}$ para o menor valor, $4,11 \mathrm{~g}$ planta $^{-1}$, no tratamento que recebeu esterco e de $80,99 \%$ sem aplicação de esterco, ou seja, de 6,99 para $1,33 \mathrm{~g} \mathrm{planta}^{-1}$. A produtividade $(644,52 \mathrm{~g}$ planta $\left.^{-1}\right)$ no tratamento com aplicação de esterco e com salinidade de $2,43 \mathrm{dS} \mathrm{m}^{-1}$ na água de irrigação foi $35,91 \%$ menor em relação ao nível de salinidade de $0,64 \mathrm{dS} \mathrm{m}^{-1}$ (Figura 6B).
Silva et al. (2013) encontraram redução menor que a no presente estudo, em que água de irrigação de alta salinidade $\left(5,0 \mathrm{dS} \mathrm{m}^{-1}\right)$ reduziu em $61,1 \%$ a produtividade, quando comparado à água de irrigação de baixa salinidade $\left(0,5 \mathrm{dS} \mathrm{m}^{-1}\right)$.

No entanto, resultados de redução elevada da produção também foram encontrados por Santana et al. (2003), que verificaram diminuição de 93,4\% na produção do feijoeiro, para o tratamento de maior salinidade $\left(5,5 \mathrm{dS} \mathrm{m}^{-1}\right)$ na água de irrigação.

Assis Júnior et al. (2007) relatam que a redução na produtividade ocasionada pela salinidade devese, em parte, às reduções no crescimento vegetativo e na assimilação líquida de carbono, durante as fases de floração e frutificação, associadas aos efeitos osmóticos.

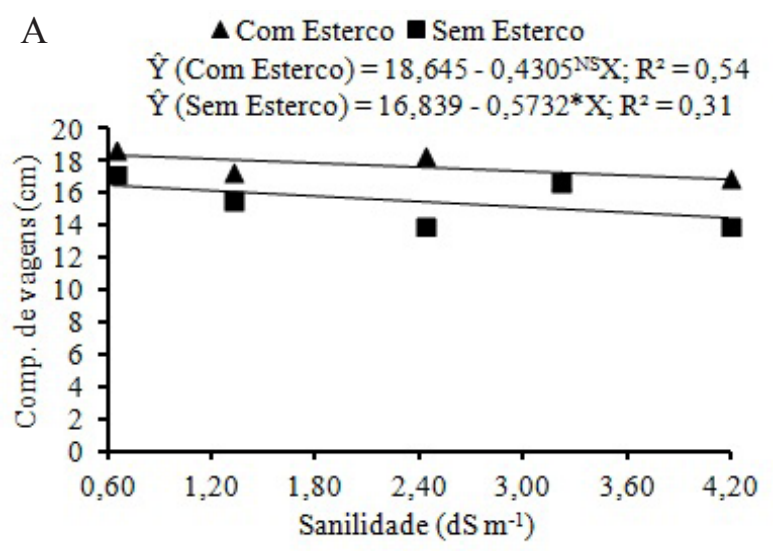




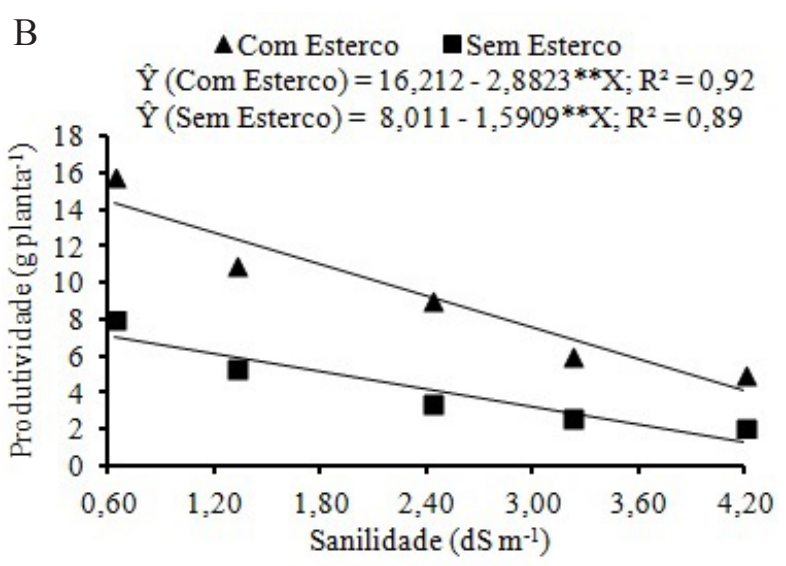

Figura 6. Comprimento de vagens (A) e produtividade (B) de feijão-caupi irrigado utilizando água com diferentes níveis de salinidade e com e sem aplicação de esterco. IF Baiano - Campus Guanambi, 2014.

As variáveis produtivas de feijão-caupi foram todas afetadas pelos níveis crescentes da salinidade da água. De acordo Ayers \& Westcot (1999), a utilização de águas salinas tem sido um problema, visto que promove o acúmulo de sais na zona radicular e reduz a produtividade da maioria das culturas. Esta diminuição da produtividade esta relacionada aos processos osmóticos, tóxicos e nutricionais do estresse salino, que afetam a assimilação liquida de $\mathrm{CO}_{2}$, inibe a expansão foliar e aceleram a senescência de folhas maduras, reduzindo, consequentemente, a área destinada ao processo fotossintético e a produção total de fotoassimilados, afetando assim, a produção de grãos da cultura (LARCERDA et al., 2003).

Semelhantes ao comportamento das variáveis de crescimento, as de produção também apresentaram valores maiores quando se aplicou o esterco bovino dentro dos diferentes níveis de salinidade. Segundo Sousa et al. (2014) o uso de fertilizantes orgânicos provenientes de resíduos de origem animal pode atenuar os efeitos danosos da salinidade da água de irrigação sobre as plantas. Isso se deve as melhorias nas propriedades do solo principalmente quanto a maior disponibilização de nutrientes para plantas.

\section{CONCLUSÕES}

- Todas as variáveis analisadas foram influenciadas pela salinidade da água de irrigação promovendo redução do menor para o maior nível de salinidade.

- Quando não se aplicou esterco houve maiores reduções para as variáveis avaliadas com os níveis crescentes da salinidade da água de irrigação.

- A aplicação de esterco bovino contribuiu para diminuir os efeitos da salinidade da água de irrigação.

\section{REFERÊNCIAS BIBLIOGRÁFICAS}

ASSIS JÚNIOR, J.O.; LACERDA, C.F.; SILVA, F.B.; SILVA, F.L.B.; BEZERRA, M.A.; GHEYI, H.R. Produtividade do feijão-de-corda e acúmulo de sais no solo em função da fração de lixiviação e da salinidade da água de irrigação. Engenharia Agrícola, Jaboticabal, v.27, n.3, p.702-713, 2007.

AYERS, R.S.; WESTCOT, D.W. A qualidade da água na agricultura. Campina Grande: UFPB (Estudos FAO: Irrigação e Drenagem, 29). p.153, 1999.

BELTRÃO JÚNIOR, J.A.; CRUZ, J.S.; SOUZA, E.C.; SILVA, L.A. Rendimento do feijão-caupi adubado com diferentes doses de biofertilizante orgânico produzido através da biodegradação acelerada de resíduos do coqueiro no município de Trairí - CE. Irriga, Botucatu, Edição Especial, v.1, n.1, p.423-437, 2012.

BRASILEIRO, R.S. Alternativas de desenvolvimento sustentável no semiárido nordestino: da degradação à conservação. Revista Scientia Plena, Aracaju, v.5, n.5, p.1-12, 2009.

COELHO, J.B.M.; BARROS, M.F.C.; BEZERRA NETO, E.; CORREA, M.M. Comportamento hídrico e crescimento do feijão vigna cultivado em solos salinizados. Revista Brasileira de Engenharia Agrícola e Ambiental, Campina Grande, v.17, n.4, p.379-385, 2013.

CONAB - Companhia Nacional de Abastecimento. Acompanhamento da safra brasileira de grãos. v.8 - Safra 2015/16 - Oitavo levantamento, Brasília, p.1-178, maio 2016. Disponível em: $<$ http://www.conab.gov.br/OlalaCMS/uploads/ 
arquivos/16 $05 \quad 10 \quad 09 \quad 03 \quad 26$ boletim graos maio 2016.pdf $>$. Acesso em: 12 de maio de 2016.

DIAS, N.D.; BLANCO, F.F. Efeitos dos sais no solo e na planta. In: GHEYI, H.R.; DIAS, N.S.; LACERDA, C.F. Manejo da salinidade na agricultura: Estudos básicos e aplicados. Fortaleza: Instituto Nacional de Ciência e Tecnologia em Salinidade. 2010, p.129-140.

DONATO, S.L.R.; LÉDO, A.A.; PEREIRA, M.C.T.; COELHO, E.F.; COTRIM, C.E. Estado nutricional de bananeiras tipo prata sob diferentes sistemas de irrigação. Pesquisa Agropecuária Brasileira. Brasília, v.45, n.9, p.980-988, 2010.

ELLIS, R.H.; LAWER, R.J.; SUMMERFIELD, R.J.; ROBERTS, E.H.; CHAY, P.M.; BROUWER, J.B.; ROSE, J.L.; YEATES, S.J. Towards the reliable prediction of time to flowering in six annual crops. III. Cowpea (Vigna unguiculata). Experimental Agriculture, London, v.30, n.1, p.17-29, 1994.

LACERDA, C.F.; CAMBRAIA, J.; CANO, M.A.O.; RUIZ, H.A.; PRISCO, J.T. Solute accumulation and distribution during shoot and leaf development in two sorghum genotypes under salt stress. Environmental and Experimental Botany, Holanda, v.49, n.2, p.107-120, 2003.

LARCHER, W. Ecofisiologia vegetal. São CarlosSP: Ed. Rima Artes e Textos, p.550, 2006.

LIMA, C.J.G.S.; OLIVEIRA, F.A; MEDEIROS, J.F.; OLIVEIRA, M.K.T.; JÚNIOR, A.B.A. Resposta do feijão caupi a salinidade da água de irrigação. Revista Verde, Mossoró, v.2, n.2, p.7986, 2007.

MUNNS, R.; TESTER, M. Mechanisms of Salinity Tolerance. Annuario journal Plant Biology, Canberra, v.1, n.59, p.651-81, 2008.

NASCIMENTO, R.; NASCIMENTO, D.A.M.; SILVA, D.A.; ALVES, A.G. Alterações nos teores de clorofilas em plantas de feijão-caupi cultivadas sob diferentes fontes de nitrogênio. Revista
Educação Agrícola Superior, Brasília, v.27, n.2, p.94-96, 2012.

PEREIRA, R.F.; LIMA, A.S.; MAIA FILHO, F.C.F.; CAVALCANTE, S.N.; SANTOS, J.G, R.; ANDRADE, R. Produção de feijão vigna sob adubação orgânica em ambiente semiárido. Agropecuária Científica no Semiárido, Patos, v.9, n.2, p.27-32, 2013.

DEVELOPMENT CORE TEAM. language and environment for statistical computing, Vienna, Austria: Foundation for Statistical Computing, 2012. Disponível em: <https://www.r-project. org/> . Acesso em: 10 de fevereiro de 2016.

RICHARDS, L.A. Diagnosis and improvement of saline and alkali soils. Washington: US Department of Agriculture, 1954. p.160. USDA Agricultural Handbook, 60.

SILVA, F.E.O.; MARACAJÁ, P.B.; MEDEIROS, J.F.; OLIVEIRA, F.A.; OLIVEIRA, M.K.T. Desenvolvimento vegetativo do feijão caupi irrigado com água salina em casa de vegetação. Revista Caatinga, Mossoró, v.22, n. 3, p.156-159, 2009.

SILVA, F.L.B.; LACERDA, C.F.; SOUSA, G.G.; NEVES, A.L.R.; SILVA, G.L.; SOUSA C.H.C. Interação entre salinidade e biofertilizante bovino na cultura do feijão-de-corda. Revista Brasileira de Engenharia Agrícola e Ambiental, Campina Grande, v.15, n.4, p.383-389, 2011 b.

SILVA, I.N.; FONTES, L.O.; TAVELLA, L.B.; OLIVEIRA, J.B.; OLIVEIRA, A.C. Qualidade de água na irrigação. Agropecuária Científica no Semi-Árido, Patos, v.7, n.3, p.1-15, 2011 a.

SILVA, J.L.A.; MEDEIROS, J.F.; ALVES, S.S.V.; OLIVEIRA, F.A.; SILVA JUNIOR, M.J.; NASCIMENTO, I.B. Uso de águas salinas como alternativa na irrigação e produção de forragem no semiárido nordestino. Revista Brasileira de Engenharia Agrícola e Ambiental, Campina Grande, v.18, (Suplemento), p.S66-S72, 2014. 
SILVA, F.L.B.; LACERDA, C.F.; NEVES, A.L.R.; SOUSA, G.G.; SOUSA, C.H.C.; FEERIRA, F.J. Irrigação com águas salinas e uso de biofertilizante bovino nas trocas gasosas e produtividade de feijão-de-corda. Irriga, Botucatu, v.18, n.2, p.304317, 2013.

SILVEIRA, J.A.G.; ARAÚJO, S.A.M.; LIMA, J.P.M.S.; VIÉGAS, R.A. Roots and leaves display contrasting osmotic adjustment mechanisms in response to $\mathrm{NaCl}$-salinity in Atriplex numularia. Environmental and Experimental Botany, Holanda, v.66, n.1, p.1-8, 2009.

SOUSA, G.G.; VIANA, T.V.A.; LACERDA, C.F.; AZEVEDO, B.M.; SILVA, G.L.; COSTA, F.R.B. Estresse salino em plantas de feijão-caupi em solo com fertilizantes orgânicos. Revista Agro@ mbiente On-line, Boa Vista, v.8, n.3, p.359-367, 2014.

SOUSA, R.A.; LACERDA, C.F.; AMARO FILHO, J.; HERNANDEZ, F.F.F. Crescimento e nutrição mineral do feijão-de-corda em função da salinidade e da composição iônica da água de irrigação. Revista Brasileira de Ciências Agrárias, Recife, v.2, n.1, p.75-82, 2007.

SOUZA, R.P.; MACHADO, E.C.; SILVEIRA, J.A.G.; RIBEIRO, R.V. Fotossíntese e acúmulo de solutos em feijoeiro caupi submetido à salinidade. Pesquisa Agropecuária Brasileira, Brasília, v.46, p.587-592, 2011.

TRAVASSOS, K.D.; GHEYI, H.R.; SOARES, F.A.L.; BARROS, H.M.M.; DIAS, N.S.; UYEDA, C.A.; SILVA, F.V. Crescimento e desenvolvimento de variedades de girassol irrigado com água salina. Irriga, Botucatu, edição especial, p.324-339, 2012.

ZANDONADI, D.B.; SANTOS, M.P; MEDICI, L.O.; SILVA, J. Ação da matéria orgânica e suas frações sobre a fisiologia de hortaliças. Horticultura Brasileira, Brasília, v.32, n.1, p.1420, 2014. 